\title{
EUROPEAN DESIGN RECOMMENDATIONS FOR SIMPLE JOINTS IN STEEL STRUCTURES
}

\author{
J.-P. Jaspart* and J.-F. Demonceau* \\ * ArGEnCo Department, Liège University \\ E-mail: Jean-Pierre.Jaspart@ulg.ac.be
}

Keywords: Joint classification and modelling, simple joints, ductility, rotation capacity.

\begin{abstract}
In the last twenty years, numerous researches have been devoted throughout Europe to the behaviour of semi-rigid and partial-strength joints in steel structures. These efforts progressively led to the publication of normative documents, design recommendation and guidelines and to the development of various design tools for practitioners. On the contrary rather little attention has been paid to the design of simple joints. In this paper, design recommendations for such joints are presented. They result from deep comparative studies of existing national codes and extensive discussions within the Technical Committee 10 "Connections » of the European Convention for constructional Steelwork (ECCS). The publication of this material as "European recommendations for the design of simple joints in steel structures" should be achieved in 2008.
\end{abstract}

\section{INTRODUCTION}

In some countries of the European Union, design rules for simple structural joints already exist. Unfortunately, these recommendations do not cover all the types of failure and give sometimes significantly different design rules for a typical failure mode.

In a first step, a comparative study [1] of available design rules for simple connections has been made. In this work, reference is made to different normative documents or design recommendations:

- $\quad$ Eurocode 3 [2] and its Part 1.8 [3];

- $\quad$ BS5950 [4] and BCSA-SCI recommendations [5];

- $\quad$ NEN $6770[6,7]$;

- $\quad$ German "Ringbuch" [8];

$$
\text { - } \quad \text {... }
$$

Each of these documents possesses its own application field which favours different failure modes. So, the comparison between them is difficult.

With the aim of establishing a full design approach according to the general design principles stated in Eurocode 3, preliminary design sheets for header plate and fin plate connections have been prepared at Liège University [9]and discussed at several meetings of the Technical Committee 10 « Connections » of the European Convention for Constructional Steelwork (ECCS). Progressively this has led to the drafting of so-called "European recommendations for the design of simple joints in steel structures". These ones should be published in 2008 [11].

In a few years, it is expected that the practical design recommendations presented in this publication or in its eventual revised version will replace, in every country, the national normative documents or recommendations. In this way, it will simplify the free trade between the different European countries.

In the present paper, the main topics covered by this forthcoming publication are addressed: joint classification, joint modelling, design requirements in terms of ductility and rotation capacity, resistance properties ... Finally a worked example illustrates the application of the proposed design rules to a specific type of joint. 


\section{SCOPE AND FIELD OF APPLICATION}

Simple structural joints are commonly met in steel framed buildings but they can be used also in other types of structures, such as masts, bridges ...

The field of application covered by the European recommendations may be summarized as follows:

- Types of connected elements:

I or $\mathrm{H}$ beams;

I or H columns (with a possible easy extension to RHS and CHS columns).

- Types of loading:

Joints subject to predominantly static or quasi-static loading. Fatigue aspects are not considered. The resistance of the joints is checked under shear and tying forces. The shear forces correspond to usual loading conditions of the structure during its life. Tying forces are also addressed; these ones develop when the frame is subjected to an explosion or when a supporting column is lost under exceptional events.

- Steel grades:

Steel grades S 235, S 275, S 355, S 420 and S 460.

- Possible joint configurations (few examples are illustrated in Figure 1):

Single-sided and double-sided beam-to-column major or minor axis joint configurations.

Single-sided or double-sided beam-to-beam joint configurations with un-notched, single-notched or double-notched supported beams.

Beam splices.

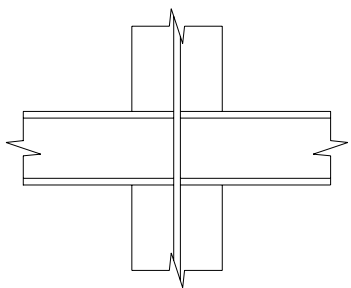

(a) Double-sided beam-to-column minor axis joint configuration

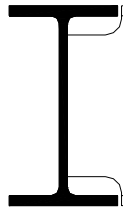

(b) Single-sided beam-to-beam joint configuration with a double-notched supported beam

Figure 1: Examples of covered joint configurations 


\section{- Types of fasteners:}

Fillet welds.

Normal bolts and high strength bolts. The second class can be used for preloaded bolts which are characterized by a slip-type resistance mode in shear. In the design recommendations, only nonpreloaded bolts are explicitly covered. The extension of the rules to preloaded bolts is not at all a difficulty and should be worked out when preparing a first revised version of the publication.

- Types of connections:

Three connection types traditionally used to connect a beam to a column or a beam to a beam are considered; they are specified below.

\section{Header plate connections}

The main components of a header plate connection are shown in Figure 2: a steel plate, a fillet weld on both sides of the supported beam web and two single or two double vertical bolt lines. The plate is welded to the supported member and bolted to a supporting element such as a steel beam or column. Its height does not exceed the clear depth of the supported beam. The end of the supported steel beam may be un-notched, single notched or double notched.
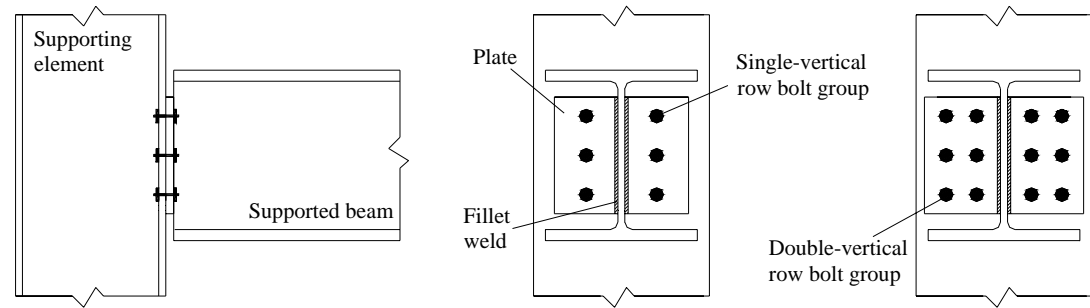

Figure 2: Header plate connection

\section{Fin plate connections}

The main components of a fin plate connection are shown in Figure 3: a fin plate, a fillet weld on both sides of the plate, and a single or double vertical bolt line. The plate is welded to a supporting member such as a steel beam or column and bolted to the web of the supported beam. The end of the supported steel beam may again be un-notched, single notched or double notched.
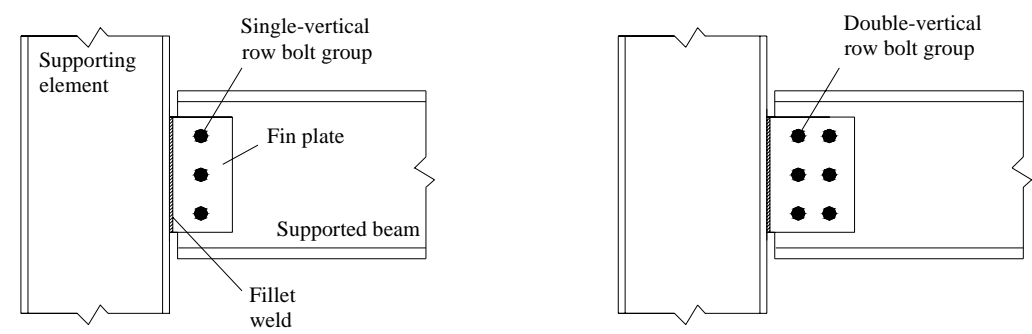

Figure 3: Fin plate connection 


\section{Web cleat connections}

A web cleat connection is characterised (see Figure 4) by two web cleats and three single or double vertical bolt lines (two on the supporting element and one on the supported member). The cleats are bolted to the supporting and supported members. Un-notched, single notched or double notched supported beams may be considered.

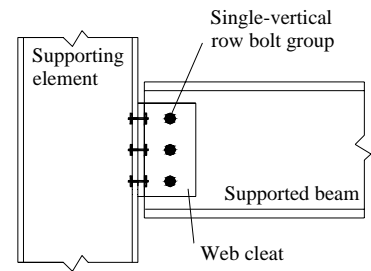

OR

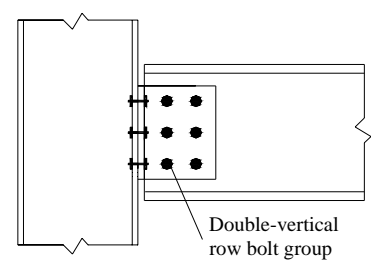

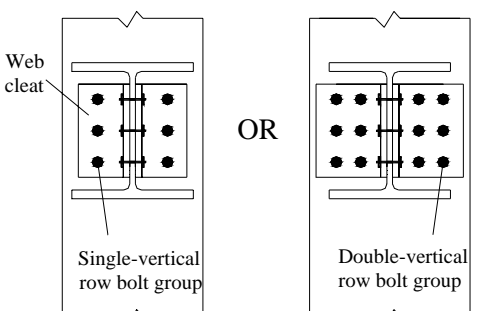

Figure 4: Web cleat connection

\section{Reference code}

The design rules presented in the present paper are based on resistance formulae provided by Eurocode 3 Part 1.8, at least as far as information is available. When this is not the case, the basic design principles prescribed by Eurocode 3 are followed.

\section{JOINT MODELLING FOR FRAME ANALYSIS AND DESIGN REQUIREMENTS}

\subsection{Generalities}

The effects of the actual response of the joints on the distribution of internal forces and moments within a structure, and on the overall deformations, should generally be taken into account; but when these effects are sufficiently small, they may be neglected.

To identify whether the effects of joint behaviour on the analysis need be taken into account, a distinction should be made between the three following types of joint modelling:

- $\quad$ simple, in which the joint may be assumed not to transfer bending moments;

- continuous, in which the behaviour of the joint may be assumed to have no effect on the analysis;

- $\quad$ semi-continuous, in which the behaviour of the joint needs to be explicitly taken into account in the analysis.

The appropriate type of joint modelling depends on the classification of the joint and on the selected procedure for structural analysis and design. 


\subsection{Eurocode 3 classification system for joints}

The joints can be classified according to the values of their main structural properties, i.e. rotational stiffness, strength in bending and rotational capacity (or ductility). The structural properties of all the joints need to correspond to the assumptions made for the structural frame analysis and for the design of the members. In particular, as far as simple joints are concerned, the available rotation capacity of the joints should be sufficient to accept the rotations evaluated in the analysis process.

In Eurocode 3 Part 1.8, joints are classified by stiffness and by strength. Ductility aspects are also to be considered; they will be more especially addressed in section 4 below.

- Classification by stiffness

This classification is only applicable to beam-to-column joint configurations. Through the comparison of its actual rotational stiffness $S_{\mathrm{j}, \text { ini }}$ with classification boundaries (Figure 5), a joint may be considered as pinned, rigid or semi-rigid.

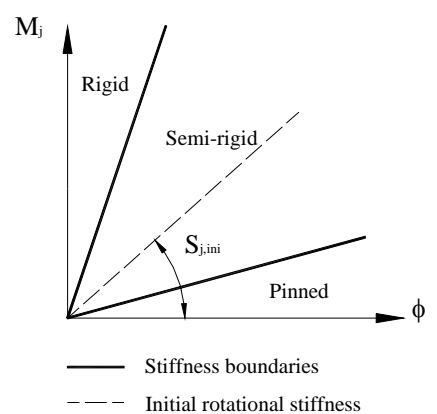

Figure 5: Boundaries for stiffness classification of joints

\section{Nominally pinned}

The joint shall be capable of transmitting the internal forces, without developing significant moments which might adversely affect the structural members. It shall be also capable of accepting the resulting rotations under the design loads.

$$
\Rightarrow \quad \text { Boundary: } \quad \mathrm{S}_{\mathrm{j}, \mathrm{ini}} \leq 0,5 \mathrm{EI}_{\mathrm{b}} / \mathrm{L}_{\mathrm{b}}
$$

\section{Rigid}

The joint behaviour is assumed not to have significant influence on the distribution of internal forces and moments in the structure, nor on its overall deformation.

$\Rightarrow \quad$ Boundary: $\quad \mathrm{S}_{\mathrm{j}, \text { ini }} \geq \mathrm{k}_{\mathrm{b}} \mathrm{EI}_{\mathrm{b}} / \mathrm{L}_{\mathrm{b}}$

where $\mathrm{k}_{\mathrm{b}}=8$ for frames where the bracing system reduces the horizontal displacement by at least $80 \% ; \mathrm{k}_{\mathrm{b}}=25$ for other frames.

\section{Semi-rigid}


The joint provides a predictable degree of interaction between members, based on the design moment-rotation characteristics of the joint. It should be able to transmit internal forces and moments.

$\Rightarrow \quad$ Boundaries: $\quad$ A joint which doesn't meet the criteria for a rigid or a nominally pinned joint shall be classified as semi-rigid.

Key values: $\mathrm{E} \quad$ is the elastic modulus of the beam material;

$\mathrm{I}_{\mathrm{b}} \quad$ is the second moment of area of the beam;

$\mathrm{L}_{\mathrm{b}} \quad$ is the beam span (distance between the axes of the supporting columns).

- Classification by strength

Through the comparison of its actual design moment resistance $\mathrm{M}_{\mathrm{j}, \mathrm{Rd}}$ with the design moment resistances of the members that it connects (Figure 6), a joint may be classified as full-strength, pinned or partial-strength.

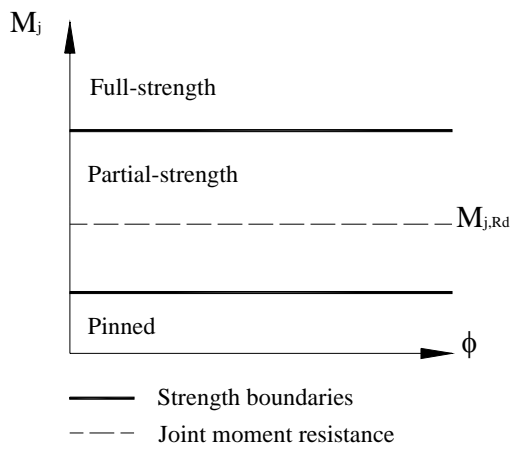

Figure 6: Boundaries for strength classification of joints

\section{Full-strength}

The design resistance of a full strength joint shall be not less than that of the connected members (Figure 7).

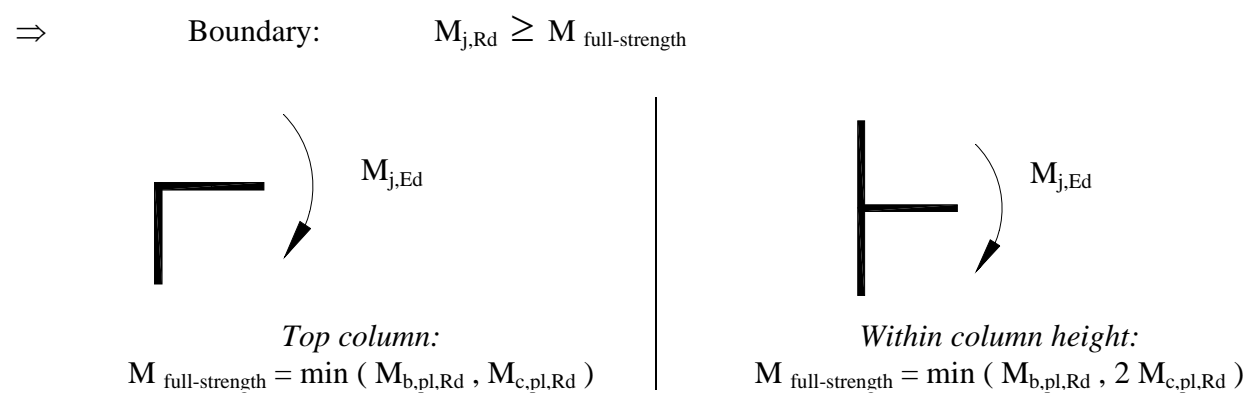

Figure 7: Full-strength resistance 


\section{Nominally pinned}

The joint shall be capable of transmitting the internal forces, without developing significant moments which might adversely affect the members of the structure. It shall also be capable of accepting the resulting rotations under the design loads.

$$
\Rightarrow \quad \text { Boundary: } \quad \mathrm{M}_{\mathrm{j}, \mathrm{Rd}} \leq 0,25 \mathrm{M}_{\text {full-strength }}
$$

\section{Partial-strength}

A joint which doesn't meet the criteria for full-strength or nominally pinned joints should be considered to have a partial-strength resistance.

Key values: $\mathrm{M}_{\mathrm{b}, \mathrm{pl}, \mathrm{Rd}} \quad$ is the plastic moment resistance of the beam;

$\mathrm{M}_{\mathrm{c}, \mathrm{pl}, \mathrm{Rd}} \quad$ is the plastic moment resistance of the column (possibly reduced by axial or shear forces in the column).

\subsection{Eurocode 3 joint modelling}

The joint modelling depends on the joint classification (see above) and on the selected process for structural frame analysis and design. As said before, Eurocode 3 considers three types of joint modelling (simple, continuous and semi-continuous) according as the effects of joint behaviour on the analysis can be neglected or no. The appropriate type of joint modelling should be determined from Table 1.

\begin{tabular}{|c|c|c|c|}
\hline $\begin{array}{c}\text { METHOD OF GLOBAL } \\
\text { ANALYSIS }\end{array}$ & \multicolumn{3}{|c|}{ JOINT CLASSIFICATION } \\
\hline Elastic & Nominally pinned & Rigid & Semi-rigid \\
\hline Rigid-Plastic & Nominally pinned & Full-strength & Partial-strength \\
\hline Elastic-Plastic & Nominally pinned & Rigid and full-strength & $\begin{array}{c}\text { Rigid and partial-strength } \\
\text { Semi-rigid and partial-strength } \\
\text { Semi-rigid and full-strength }\end{array}$ \\
\hline TYPE OF JOINT MODEL & Simple & Continuous & Semi-continuous \\
\hline
\end{tabular}

Table 1: Type of joint model

So, in the global analysis, the joint behaviour can be replaced by [10] (Figure 8):

- $\quad$ a hinge, for the simple modelling;

- $\quad$ a rotational spring, for the semi-continuous modelling;

- $\quad$ an infinitely rigid and resistant rotational spring, for the continuous modelling.

In the global structural analysis, the hinge or spring which models the joint is assumed to be located at the intersection of the axes of the connected elements.

\subsection{Simple joint modelling}

The design rules in this guide are given for joints which are assumed not to transmit bending moments. Thus, the joints should be modelled by hinges. Unfortunately, many joints which are traditionally considered as a hinge do not fulfil the stiffness and/or strength limitations required by Eurocode 3 for nominally pinned joints.

Two different attitudes may be adopted in such a case: 
- According to the Eurocode 3 requirements, the joint is modelled by a rotational spring and is therefore considered as semi-rigid and partial-strength (what it is in reality). Its rotational stiffness, design bending resistance and shear resistance have to be evaluated and the actual properties of the joint have to be explicitly taken into consideration in the process for frame and joint design and analysis. This approach is the more scientifically correct one but it needs more complex calculations as far as the global analysis and joint design are concerned.

- Despite its actual properties, the joint is considered as a hinge and the design rules for simple joints presented in the present paper can be applied, but under strict conditions which ensure the safe character of the approach. The global analysis and the joint design are simpler in this case as they are based on a more traditional hinged (simple) approach.

\begin{tabular}{|c|c|c|c|}
\hline $\begin{array}{l}\text { TYPE OF JOINT } \\
\text { MODEL }\end{array}$ & $\begin{array}{l}\text { SINGLE-SIDED } \\
\text { CONFIGURATION }\end{array}$ & $\begin{array}{l}\text { DOUBLE-SIDED } \\
\text { CONFIGURATION }\end{array}$ & BEAM SPLICE \\
\hline Simple & 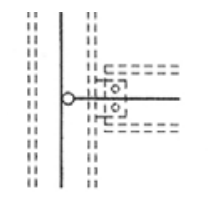 & 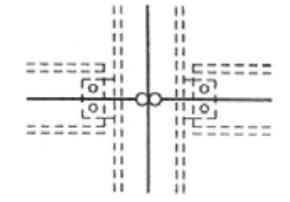 & 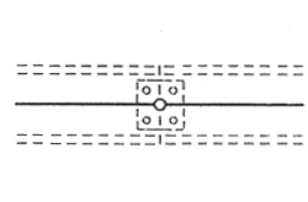 \\
\hline Continuous & 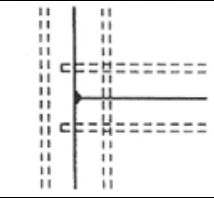 & 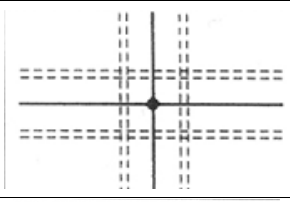 & 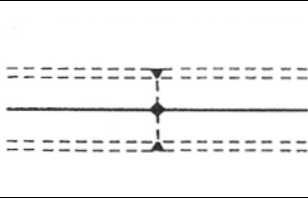 \\
\hline Semi-continuous & 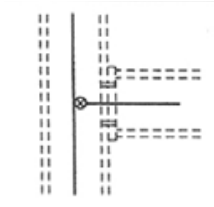 & 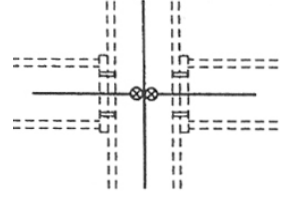 & 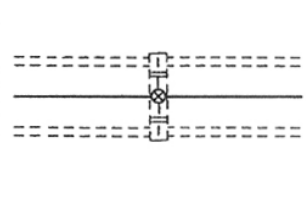 \\
\hline
\end{tabular}

Figure 8: Local joint modelling

If the second option is chosen, the joint is assumed not to transfer bending moments even if it is not the truth. Therefore bending moments develop in the joints although they are designed to resist only shear forces. This is potentially unsafe and at first sight is not basically acceptable.

But a careful examination of this problem leads to the conclusion that the "hinge assumption" is safe if the two following requirements are fulfilled:

- the joint possesses a sufficient rotation capacity;

- the joint possesses a sufficient ductility.

The first requirement relates to the rotational capacity that the joint should have, in order to "rotate" as a hinge, without developing too high internal bending moments.

The second requirement is there to ensure that the development of combined shear and bending forces into the joint is not leading to brittle failure modes (for instance, because of a rupture of a bolt or a weld). In other words, the design of the joint should allow internal plastic deformations instead of brittle phenomena.

If these two requirements (sufficient rotation capacity and ductility) are fulfilled, it can be demonstrated that to consider an actually semi-rigid joint as a nominally pinned one is safe for design purposes and, in particular, for the evaluation of:

- the frame displacements: 
the stiffness of the actual structure is always greater than that of the hinged one, and all the actual displacements are therefore lower than the calculated ones;

- the plastic failure loading:

as the actual bending strength of the joint is higher than the considered one (equal to zero), the first order plastic resistance of the frame is higher than the one evaluated on the basis of a hinge behaviour;

- the linear elastic critical instability load:

the transversal stiffness of the actual structure is larger than the one of the structure with nominally pinned joints, and the rotational restraints at the end of the columns in the actual structure are higher than those calculated with a hinge assumption; this ensures the safe character of the hinge assumption as far as global and local instability are concerned;

- the actual elasto-plastic instability load:

the actual stiffness of the structure is greater than the considered one but the actual internal forces are more important than those acting in the structure with nominally pinned joints; nevertheless, various studies ([12], [13] and [14]) show that the "hinged" approach is safe.

For further explanations, see [9].

In the present paper, the design recommendations relate to the "hinge model". In [11], specific design requirements ensuring safety will be presented for each connection type.

\subsection{Summary of design requirements}

As said before, the internal forces in the joint are here determined by a structural analysis based on simple joint modelling. The hinges are assumed to be located at the intersection of the axes of the connected elements. As a result of this structural analysis, the maximum applied shear force and rotation in the joints, respectively $\mathrm{V}_{\mathrm{Ed}}$ and $\phi_{\text {required, }}$ are obtained.

From the geometrical properties of the joints and the mechanical properties of their constitutive materials, the available rotation capacity of any joint, $\phi_{\text {available, can be estimated, as well as its design }}$ shear resistance, $\mathrm{V}_{\mathrm{Rd}}$. To ensure the validity of this approach, some ductility requirements have to be satisfied and the available rotation of the joint has to be higher than the required one. Finally, the joint will be considered as acceptable if the applied shear force does not exceed the design shear resistance.

Sometimes, the evaluation of the resistance to tying forces is requested for robustness purposes.

\section{PRACTICAL WAYS TO SATISFY THE DUCTILITY AND ROTATION REQUIREMENTS}

\subsection{General principles}

A simple joint is nothing else than an idealisation of the reality. Joints like those studied in this paper undergo a significant internal rotation but transfer some bending moments. As explained above, to ensure the safety of the simple joint model, some requirements for sufficient ductility and rotation capacity are necessary.

These requirements can be written for each considered connection type, in the form of simple criteria based on the mechanical and geometrical characteristics of the different components forming the connection.

The rotation capacity requirements provide to the hinge a sufficient rotation without developing too significant bending moments which might adversely affect the members of the structure. These criteria are often expressed as geometrical limitations.

The ductility requirements avoid the occurrence of brittle failures, especially in bolts and welds, and possibly buckling. Their derivation is more complex. In the "hinged" structural analysis, the joint is assumed to be only subjected to a shear force. In reality, a bending moment and a shear force are acting simultaneously on the joint. In an "applied shear force - applied bending moment" graph (Figure 9), the evolution of the actual and idealised loading histories can be represented by two paths. The first is a 
horizontal one $\left(\mathrm{M}_{\mathrm{Ed}}=0\right)$ and the second an oblique one. The inclination of the actual loading path depends on the relative stiffness between the joint and the connected elements.

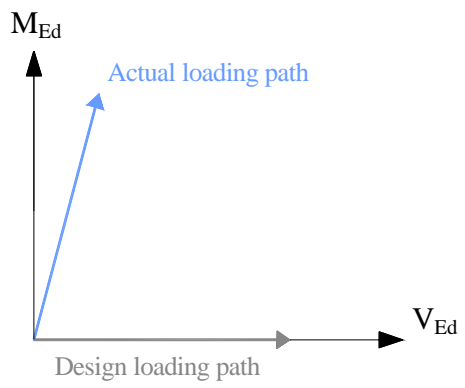

Figure 9: Loading paths

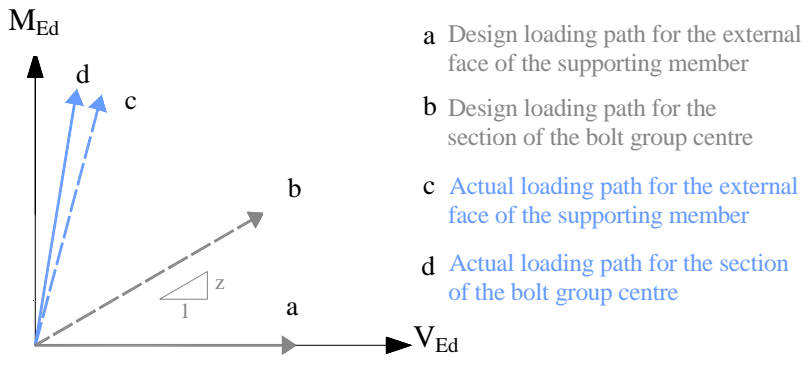

Figure 10: Loading paths for a fin plate connection

Note: For fin plate connections, two different cross-sections inside the joint have to be considered separately. The first is located at the external face of the supporting member; while the second is through the centre of the bolt group. The actual loading situation is different in these two sections, so leading to two distinct $\mathrm{M}_{\mathrm{Ed}}-\mathrm{V}_{\mathrm{Ed}}$ paths in the diagram shown in Figure 10.

If a "hinge" model is considered, the first section is assumed to transfer only shear forces $\left(\mathrm{M}_{\mathrm{Ed}}=0\right)$ while the second one, in accordance with equilibrium, transfers the same shear force $\mathrm{V}_{\mathrm{Ed}}$ and a bending moment $\mathrm{M}_{\mathrm{Ed}}$ equal to $\mathrm{V}_{\mathrm{Ed}}$. $\mathrm{z}$. $\mathrm{z}$ is defined as the distance between the external face of the supporting element and the centre of the bolt group.

The design resistance of each component of the joint can also be represented in a "shear force bending moment" graph. Depending on whether this resistance is influenced by the applied bending moment, its representation will be a curve or a vertical line. Figure 11 illustrates it for three possible failure modes in a fin plate connection. The relative positions of the different resistance curves or lines depends on the geometrical and mechanical characteristics of the joint components.

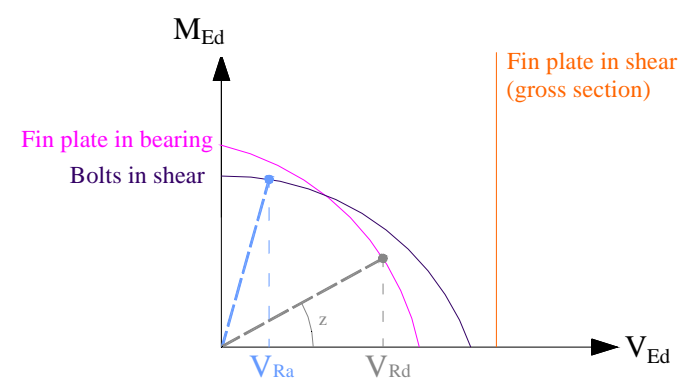

Figure 11: Design resistances for some components of a fin plate connection and principle for the derivation of the shear resistance of the joint

In reality, the actual shear resistance, $\mathrm{V}_{\mathrm{Ra}}$, of the joint could be defined at the intersection between the actual loading path, in the appropriate cross-section, and the design resistance curves or lines of the 
weakest component (Figure 11). If a similar principle is applied to the design loading path, a design shear resistance, $\mathrm{V}_{\mathrm{Rd}}$, is then obtained.

If the failure mode corresponding to the $V_{R a}$ value is a brittle one, the design shear resistance $V_{R d}$ is seen to be an unsafe estimation of the joint resistance (Figure 12.a). The only way to reach the design shear resistance $\mathrm{V}_{\mathrm{Rd}}$, is to rely on a plastic redistribution of internal forces inside the joint, as shown on Figure 12.b.
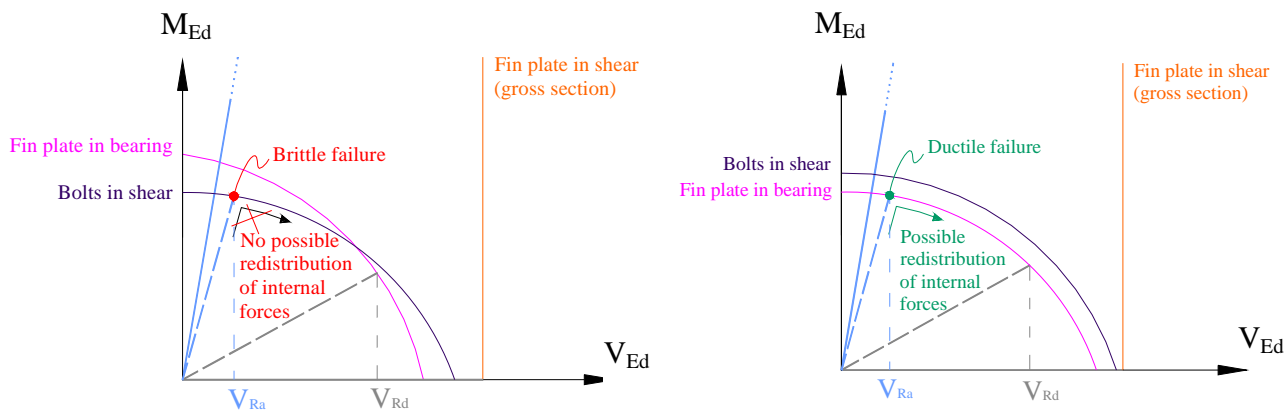

(a) Premature brittle failure

(b) Possible plastic redistribution of internal forces

Figure 12: Determination of the shear resistance of the joint

As a conclusion, the ductility requirements will aim to ensure that the move from the actual to the design shear resistances may occur, as a result of a plastic redistribution of internal forces inside the joint.

\subsection{Header plate connection}

In the next paragraphs, the design requirements to be fulfilled to allow sufficient rotation capacity and ductility are specified for one of the connection types: the header plate connection. For other types, reference is to be made to [11].

\section{- Design requirements for sufficient rotation capacity}

To enable rotation without increasing too much the bending moment which develops into the joint, contact between the lower beam flange and the supporting member has to be strictly avoided. So, it is imperative that the height $h_{p}$ of the plate is less than that of the supported beam web (Figure 14):

$$
\mathrm{h}_{\mathrm{p}} \leq \mathrm{d}_{\mathrm{b}}
$$

where $d_{b}$ is the clear depth of the supported beam web.

If such a contact takes place, a compression force develops at the place of contact; it is equilibrated by tension forces in the bolts and a significant bending moment develops (Figure 13). 

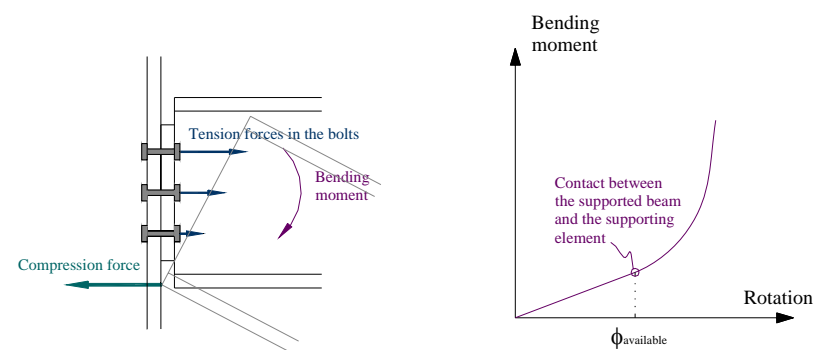

Figure 13: Contact and evolution of the bending moment

The level of rotation at which the contact occurs is obviously dependent on the geometrical characteristics of the beam and of the header plate, but also on the actual deformations of the joint components.

In order to derive a simple criterion that the user could apply, before any calculation, to check whether the risk of contact may be disregarded, the following rough assumptions are made (see Figure 14):

- the supporting element remains un-deformed;

- the centre of rotation of the beam is located at the lower extremity of the header plate.

On the basis of such assumptions, a safe estimation (i.e. a lower bound) of the so-called "available rotation of the joint" $\phi_{\text {available }}$ may be easily derived:

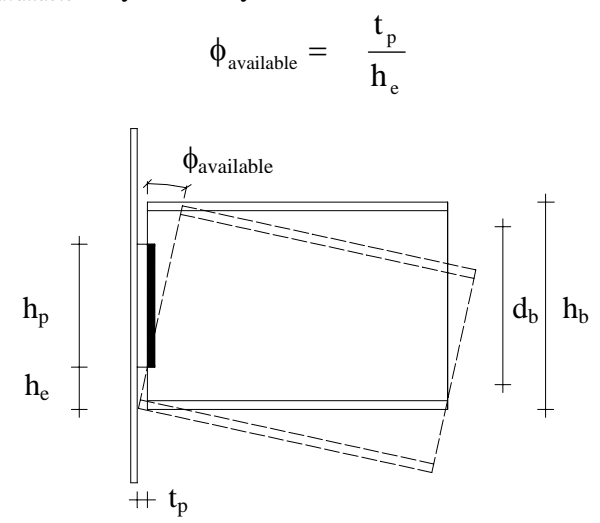

Figure 14: Geometrical characteristics of the joint and illustration of contact between the beam and the supporting element

This available rotation has to be greater than the "required rotation capacity" which varies according to the structural system and loading. A simple criterion ensuring the sufficient joint rotation capacity may be written as:

$$
\phi_{\text {available }}>\phi_{\text {required }}
$$

For instance, the required rotation capacity, for a beam (length $L$ and inertia $I$ ) simply supported at its extremities and subjected to a uniformly distributed load (factored load $\gamma p$ at ULS), is given by:

$$
\phi_{\text {required }}=\frac{\gamma \mathrm{p} \mathrm{L}^{3}}{24 \mathrm{EI}}
$$

By expressing that $\phi_{\text {available }}>\phi_{\text {required }}$, a simple criterion ensuring a sufficient joint rotation may be derived: 


$$
\frac{\mathrm{t}}{\mathrm{h}_{\mathrm{e}}}>\frac{\gamma \mathrm{PL}^{3}}{24 \mathrm{EI}}
$$

Similar criteria may be derived for other load cases [11].

- Design requirements for sufficient joint ductility

As bending moments develop in the joint, the bolts and the welds are subjected to tension forces in addition to shear forces. Premature failure of those elements which exhibit a brittle failure and which are more heavily loaded in reality than in the calculation model has therefore to be strictly avoided. Simple related criteria should therefore be proposed.

\section{Criterion to avoid premature bolt failure because of tension forces}

In Eurocode 3, a criterion based on the T-stub approach ensures that a yield lines mechanism develops in the plate before the strength of the bolts is exhausted (see [3]); its background is given in [15].

According to this criterion, at least one of the two following inequalities (1) and (2) has to be satisfied:

$$
\begin{aligned}
\frac{\mathrm{d}}{\mathrm{t}_{\mathrm{p}}} & \geq 2,8 \sqrt{\frac{\mathrm{f}_{\mathrm{yp}}}{\mathrm{f}_{\mathrm{ub}}}} \\
\frac{\mathrm{d}}{\mathrm{t}_{\mathrm{cf}}} & \geq 2,8 \sqrt{\frac{\mathrm{f}_{\mathrm{ycf}}}{\mathrm{f}_{\mathrm{ub}}}} \quad \text { for a supporting column flange }
\end{aligned}
$$

where: $\quad \mathrm{d} \quad$ is the nominal diameter of the bolt shank;

$t_{p} \quad$ is the thickness of the header plate;

$\mathrm{t}_{\mathrm{cf}} \quad$ is the thickness of the supporting column flange;

$\mathrm{f}_{\mathrm{yp}} \quad$ is the yield strength of the steel constituting the header plate;

$\mathrm{f}_{\mathrm{ycf}}$ is the yield strength of the steel constituting the supporting column flange;

$f_{u b} \quad$ is the ultimate strength of the bolt.

However, such a criterion does not ensure that the whole shear capacity of the bolt may be considered when evaluating the shear resistance of the joint. In fact, when this requirement is satisfied, it may be demonstrated: that the tension force in the bolts may amount $0,5 B_{t . R d}$, i.e. $50 \%$ of the design tension resistance $\mathrm{B}_{\mathrm{t}, \mathrm{Rd}}$ of the bolts and that, for such a tension force, the actual shear resistance only amounts $64 \%$ of the full shear resistance of the bolts (according to the EC 3 resistance formula for bolts in shear and tension).

This looks at first to be disappointing as the user tries to maximise the shear resistance of the joint. It may be argued though that only the bolts located in the upper half of the header plane are affected by such a reduction, as the others are located in a compression zone, and are therefore not subjected to tension forces.

So finally a reduction is taken into consideration by multiplying the total resistance of the bolts in shear by a factor 0,8 (i.e. a reduction factor of 0,64 for half of the bolts located in the upper half of the header plate $-0,5 \cdot[1+0,64] \approx 0,8)$.

\section{Criterion to avoid premature weld failure}

The welds must be designed according to EC3 Part 1.8. In the case of relatively small loads in relation to the capacity of the web, application of the rules in 4.5.3.2 of Part 1.8 may lead to rather thin welds. If the rupture strength of those thin welds is lower than the yield strength of the weakest 
of the connected parts, the connection has so little deformation capacity that it usually is not sufficient to accommodate effects due to imposed deformations, etc. In such a case the connection will behave in a brittle way.

To avoid this, the welds can be designed "full strength". The rupture strength of full strength welds is greater than the rupture strength of the adjacent plate; so, in the case of overloading, the plate will fail before the welds. This is a safe design but not always necessary, taking into account the requirement that the welds should at least be able to ensure yielding of the plate before rupture in the welds. In the IIW recommendations of 1976 it is stated that, if the welds are designed at $70 \%$ of the full strength, yielding of the plate is ensured before rupture of the welds. After the reevaluation of weld design formulae included in the ENV version of EC3, which gave some smaller weld sizes than in IIW rules, it was decided in the Dutch standard NEN 6770 [6] to modify the 70 $\%$ to $80 \%$. This recommendation is adopted here and in [11] even if the rule does not exist in Part 1.8 of EC3.

\section{- Conclusions}

If the rotation capacity and ductility requirements specified above are satisfied, the shear resistances of all the constitutive components are then evaluated and the design shear resistance of the connection corresponds to the weakest one, as illustrated in Figure 15. This is permitted because all the possible detrimental effects linked to "bending-shear" interaction phenomena are integrated into the ductility requirements.

In reality, the first component to yield is not necessarily the weakest one, in terms of shear resistance, and two different situations may occur (Figure 15). In the first case (Figure 15.a), the same failure mode is obtained by following the actual and design loading paths. For the second case (Figure 15.b), the failure mode obtained with the actual loading path is not the weakest one, but is ductile enough to allow a plastic redistribution of internal forces to take place until the design shear resistance is reached.

Finally - and this is of importance for practice - it has to be noted that the design requirements are first to be checked before any evaluation of shear resistance is made. This avoids unnecessary calculations.

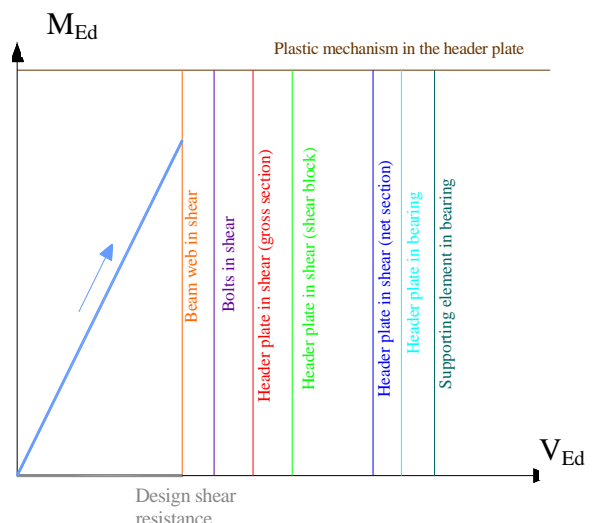

(a) One single failure mode

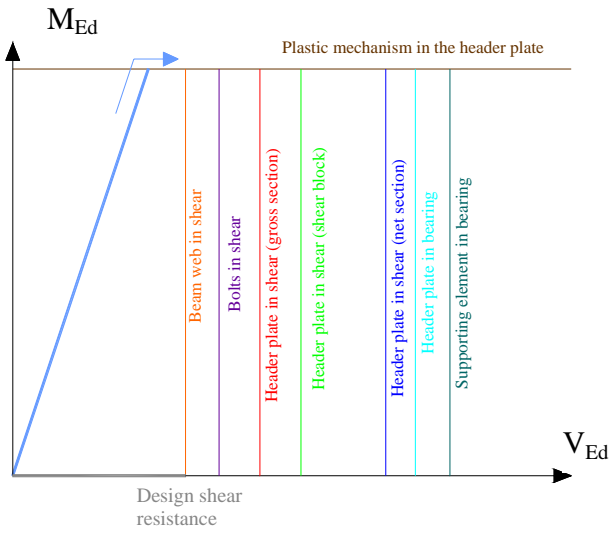

(b) Different failure modes

Figure 15: Possible failure modes for a header plate connection 


\section{DESIGN SHEETS}

In [11], design sheets for practical applications are presented. They allow to check whether the connection under consideration fulfils the design requirements described in section 4, but also to evaluate easily the design shear resistance and the tying ultimate capacity of the joint.

\section{WORKED EXAMPLE}

The full design procedure is illustrated hereafter in the case of a single-sided beam-to-column joint with a header plate connection (Figure 16). Explicit references are made to clauses of Eurocode 3 Part 11 [2] and Part 1-8 [3] whenever it is possible.
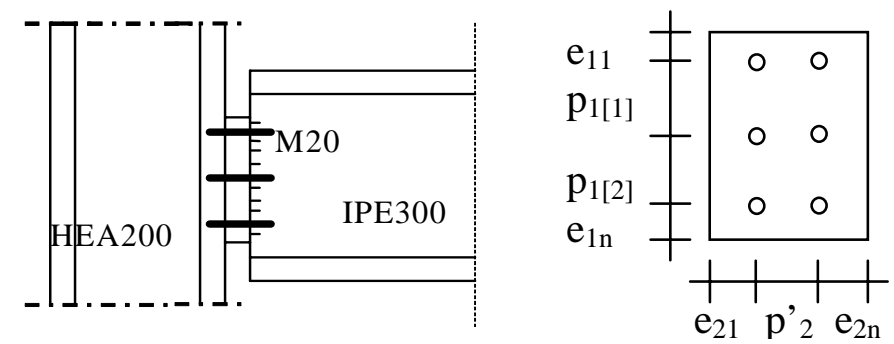

Figure 16: Single-sided beam-to-column joint with a header plate connection

- Main joint data

$\begin{array}{ll}\text { Configuration: } & \text { Beam to column flange } \\ \text { Column: } & \text { HEA 200 S 235 } \\ \text { Beam: } & \text { IPE } 300 \text { S 235 } \\ \text { Connection type: } & \text { Header plate connection } \\ \text { Header plate: } & 230 \text { x 200 x 10, S } 235\end{array}$

- Detailed characteristics

Column HEA 200, S235

$\begin{array}{ll}\text { Depth: } & \mathrm{h}=190.00 \mathrm{~mm} \\ \text { Web thickness: } & \mathrm{t}_{\mathrm{cw}}=6.50 \mathrm{~mm} \\ \text { Width: } & \mathrm{b}_{\mathrm{c}}=200.00 \mathrm{~mm} \\ \text { Flange thickness: } & \mathrm{t}_{\mathrm{cf}}=10.00 \mathrm{~mm} \\ \text { Root radius: } & \mathrm{r}=18.00 \mathrm{~mm} \\ \text { Area: } & \mathrm{A}=53.83 \mathrm{~cm}^{2} \\ \text { Inertia: } & \mathrm{I}=3692.16 \mathrm{~cm}^{4} \\ & \\ \text { Yield strength } & \mathrm{f}_{\mathrm{yc}}=235.00 \mathrm{~N} / \mathrm{mm}^{2} \\ \text { Ultimate strength } & \mathrm{f}_{\mathrm{uc}}=360.00 \mathrm{~N} / \mathrm{mm}^{2}\end{array}$

Beam IPE 300, S235
Depth:
$\mathrm{h}=300.00 \mathrm{~mm}$
Web thickness:
$\mathrm{t}_{\mathrm{bw}}=7.10 \mathrm{~mm}$
Width
$\mathrm{b}_{\mathrm{b}}=150.00 \mathrm{~mm}$ 
Flange thickness: $t_{b f}=10.70 \mathrm{~mm}$

Root radius: $\quad \mathrm{r}=15.00 \mathrm{~mm}$

Area: $\quad \mathrm{A}=53.81 \mathrm{~cm}^{2}$

Inertia: $\quad \mathrm{I}=8356.11 \mathrm{~cm}^{4}$

Yield strength: $\quad \mathrm{f}_{\mathrm{yb}}=235.00 \mathrm{~N} / \mathrm{mm}^{2}$

Ultimate strength: $f_{u b}=360.00 \mathrm{~N} / \mathrm{mm}^{2}$

Header plate 230 x 200 x 10, S 235

$\begin{array}{ll}\text { Vertical gap: } & \mathrm{g}_{\mathrm{v}}=35.00 \mathrm{~mm} \\ \text { Depth: } & \mathrm{h}_{\mathrm{p}}=230.00 \mathrm{~mm} \\ \text { Width: } & \mathrm{b}_{\mathrm{p}}=200.00 \mathrm{~mm} \\ \text { Thickness: } & \mathrm{t}_{\mathrm{p}}=10.00 \mathrm{~mm}\end{array}$

Direction of load transfer (1)

Number of bolts rows: $\quad \mathrm{n}_{1}=3$

Edge distance to first bolt row: $\quad \mathrm{e}_{11}=45.00 \mathrm{~mm}$

Pitch between bolt rows 1 and 2: $\quad \mathrm{p}_{1[1]}=70.00 \mathrm{~mm}$

Pitch between bolt rows 2 and 3: $\quad p_{1[2]}=70.00 \mathrm{~mm}$

Distance from last bolt row to edge: $\quad \mathrm{e}_{1 \mathrm{n}}=45.00 \mathrm{~mm}$

Direction perpendicular to load transfer (2)

Number of bolts rows:

Edge distance to first bolt row:

Pitch between bolt rows 1 and 2:

Distance from last bolt row to edge:

Distance from last bolt row to edge:

(column flange)

Yield strength: $\quad \mathrm{f}_{\mathrm{yp}}=235.00 \mathrm{~N} / \mathrm{mm}^{2}$

Ultimate strength: $\mathrm{f}_{\mathrm{up}}=360.00 \mathrm{~N} / \mathrm{mm}^{2}$

\section{Bolts M20, 8.8}

Tensile stress area: $\mathrm{A}_{\mathrm{s}}=245.00 \mathrm{~mm}^{2}$

Shank diameter: $\quad \mathrm{d}=20.00 \mathrm{~mm}$

Hole diameter: $\quad \mathrm{d}_{0}=22.00 \mathrm{~mm}$

Yield strength: $\quad f_{y b}=640.00 \mathrm{~N} / \mathrm{mm}^{2}$

Ultimate strength: $f_{u b}=800.00 \mathrm{~N} / \mathrm{mm}^{2}$

\section{Welds}

Throat thickness: $\mathrm{a}_{\mathrm{w}}=4.00 \mathrm{~mm}$
Length:
$\mathrm{l}_{\mathrm{w}}=230.00 \mathrm{~mm}$

\section{Safety factors}




$$
\begin{aligned}
& \gamma_{\mathrm{M} 0}=1.00 \\
& \gamma_{\mathrm{M} 2}=1.25 \\
& \gamma_{\mathrm{Mu}}=1.10
\end{aligned}
$$

\section{Applied shear force}

$$
\mathrm{V}_{\mathrm{Ed}}=200 \mathrm{kN}
$$

- Ductility and rotation requirements

\section{Rotation requirements}

(1) $h_{p} \leq d_{b}$

$$
\begin{aligned}
\mathrm{h}_{\mathrm{p}}= & 230.00 \mathrm{~mm} \\
\mathrm{~d}_{\mathrm{b}}= & \mathrm{h}-2 \mathrm{t}_{\mathrm{bf}}-2 \mathrm{r} \\
& =\quad 300.00-2 \quad 10.70-2 \quad 15.00=248.60 \mathrm{~mm} \\
\rightarrow & \text { O.K. }
\end{aligned}
$$

(2) $\phi_{\text {available }}>\phi_{\text {required }}$ we suppose that this requirement is fulfilled.

\section{Ductility requirements}

(1) $\frac{d}{t_{p}} \geq 2.8 \sqrt{\frac{f_{y p}}{f_{u b}}}$

$$
\begin{aligned}
\mathrm{d} / \mathrm{t}_{\mathrm{p}} & =2.00 \\
\mathrm{f}_{\mathrm{yp}} / \mathrm{f}_{\mathrm{ub}} & =0.29 \\
& \rightarrow 2.00 \geq 1.52 \quad \text { O.K. }
\end{aligned}
$$

(2) $\mathrm{a} \geq 0.4 \mathrm{t}_{\mathrm{bw}} \beta_{\mathrm{w}} \sqrt{3}\left(\mathrm{f}_{\mathrm{ybw}} \gamma_{\mathrm{M} 2} / \mathrm{f}_{\mathrm{ubw}} \gamma_{\mathrm{M} 0}\right)=3.21 \mathrm{~mm}$

$$
\begin{aligned}
\mathrm{t}_{\mathrm{bw}} & =7.1 \mathrm{~mm} \\
\mathrm{f}_{\mathrm{ybw}} & =235.00 \mathrm{~N} / \mathrm{mm}^{2} \\
\mathrm{f}_{\mathrm{ubw}} & =360.00 \mathrm{~N} / \mathrm{mm}^{2} \\
\beta_{\mathrm{w}} & =0.80 \\
\mathrm{a} & =4.00 \mathrm{~mm} \\
& \rightarrow \text { O.K. }
\end{aligned}
$$

- Joint shear resistance

\section{Bolts in shear}

$$
\begin{aligned}
& \mathrm{V}_{\mathrm{Rd} 1}=0,8 \mathrm{n} \mathrm{F}_{\mathrm{v}, \mathrm{Rd}}=451.58 \mathrm{kN} \\
& \mathrm{n}=6 \\
& \mathrm{~F}_{\mathrm{v}, \mathrm{Rd}}=\alpha_{\mathrm{v}} \mathrm{A} \mathrm{f}_{\mathrm{ub}} / \gamma_{\mathrm{M} 2}=94.08 \mathrm{kN}(\text { EC3 Part 1-8 Table 3.4) } \\
& \quad \alpha_{\mathrm{v}}=0.6
\end{aligned}
$$




$$
\begin{aligned}
& A=A_{S}=245.00 \mathrm{~mm}^{2} \\
& \mathrm{f}_{\mathrm{ub}}=800.00 \mathrm{~N} / \mathrm{mm}^{2}
\end{aligned}
$$

\section{Header plate in bearing}

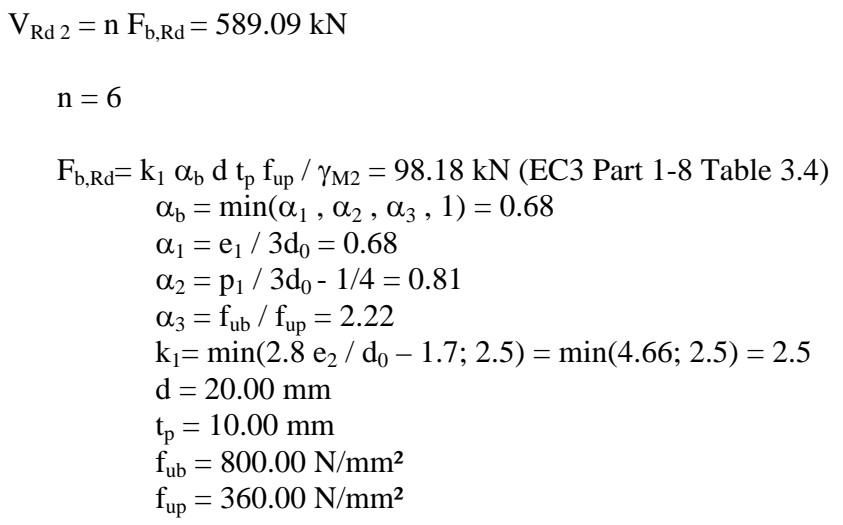

\section{Column flange in bearing}

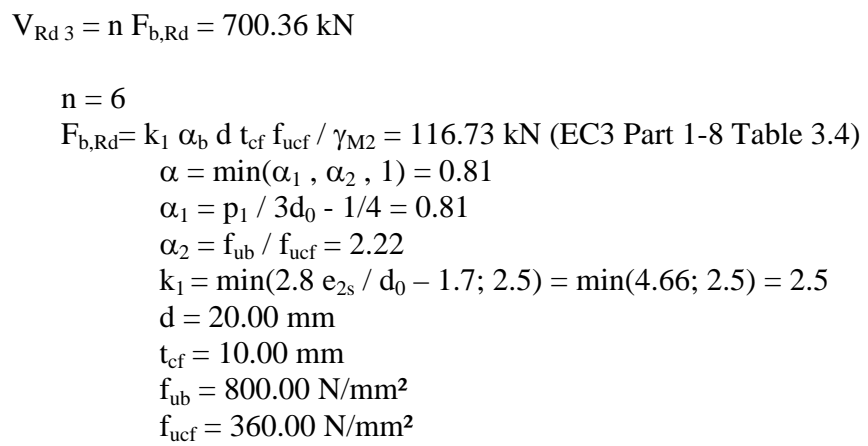

Gross section of the header plate in shear

$\mathrm{V}_{\mathrm{Rd} 4}=2 \mathrm{~F}_{\mathrm{v}, \mathrm{Rd}}=491.44 \mathrm{kN}$

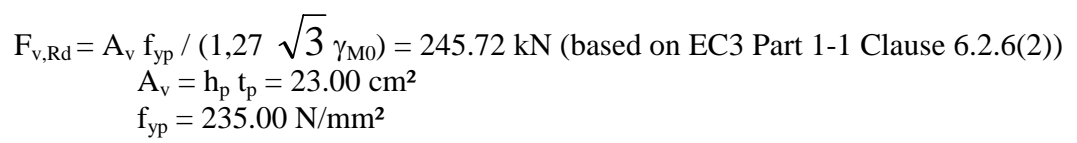

\section{Net section of the header plate in shear}

$\mathrm{V}_{\mathrm{Rd} 5}=2 \mathrm{~F}_{\mathrm{v}, \mathrm{Rd}}=545.39 \mathrm{kN}$

$$
\begin{aligned}
\mathrm{F}_{\mathrm{v}, \mathrm{Rd}}= & \mathrm{A}_{\mathrm{v}, \text { net }} \mathrm{f}_{\mathrm{up}} /\left(\sqrt{3} \gamma_{\mathrm{M} 2}\right)=272.69 \mathrm{kN} \\
& \mathrm{A}_{\mathrm{v} \text {,net }}=\left(\mathrm{h}_{\mathrm{p}}-\mathrm{n}_{1} \mathrm{~d}_{0}\right) \mathrm{t}_{\mathrm{p}}=16.40 \mathrm{~cm}^{2} \\
& \mathrm{~h}_{\mathrm{p}}=230.00 \mathrm{~mm}
\end{aligned}
$$




$$
\begin{aligned}
& \mathrm{n}_{1}=6 \\
& \mathrm{~d}_{0}=22.00 \mathrm{~mm} \\
& \mathrm{t}_{\mathrm{p}}=10.00 \mathrm{~mm} \\
& \mathrm{f}_{\text {up }}=360.00 \mathrm{~N} / \mathrm{mm}^{2}
\end{aligned}
$$

Shear block of the header plate

$\mathrm{V}_{\mathrm{Rd} 6}=2 \mathrm{~F}_{\text {eff,Rd }}=577.40 \mathrm{kN}$

$1,36 \mathrm{p}_{2}{ }^{\prime}=136.00 \mathrm{~mm} \rightarrow \mathrm{h}_{\mathrm{p}}>1,36 \mathrm{p}_{2}{ }^{\prime}$

$\mathrm{n}_{1}=3 \rightarrow \mathrm{n}_{1}>1$

$\mathrm{F}_{\text {eff,Rd }}=\mathrm{F}_{\text {eff, } 1, \mathrm{Rd}}=\mathrm{f}_{\text {up }} \mathrm{A}_{\mathrm{nt}} / \gamma_{\mathrm{M} 2}+\mathrm{f}_{\mathrm{yp}} \mathrm{A}_{\mathrm{nv}} /\left(\sqrt{3} \gamma_{\mathrm{M} 0}\right)=288.70 \mathrm{kN}$ (EC3 Part 1-8 Clause 3.10.2(2))

$A_{n t}=t_{p}\left(e_{2}-d_{0} / 2\right)=390.00 m^{2}$

$\mathrm{t}_{\mathrm{p}}=10.00 \mathrm{~mm}$

$\mathrm{e}_{2}=50.00 \mathrm{~mm}$

$\mathrm{d}_{0}=22.00 \mathrm{~mm}$

$A_{n v}=t_{p}\left(h_{p}-e_{1}-\left(n_{1}-0.5\right) d_{0}\right)=1300.00 m^{2}$

$\mathrm{n}_{1}=3$

$\mathrm{h}_{\mathrm{p}}=230.00 \mathrm{~mm}$

$\mathrm{e}_{1}=45.00 \mathrm{~mm}$

$\mathrm{f}_{\mathrm{yp}}=235.00 \mathrm{~N} / \mathrm{mm}^{2}$

$\mathrm{f}_{\text {up }}=360.00 \mathrm{~N} / \mathrm{mm}^{2}$

Header plate in bending

$\mathrm{V}_{\mathrm{Rd} 7}=\infty$

$\mathrm{h}_{\mathrm{p}}=230.00 \mathrm{~mm}$

$1,36 \mathrm{p}_{2}{ }^{\prime}=136.4 \mathrm{~mm} \rightarrow \mathrm{h}_{\mathrm{p}}>1,36 \mathrm{p}_{2}{ }^{\prime}$

\section{Beam web in shear}

$\mathrm{V}_{\mathrm{Rd} 8}=\mathrm{F}_{\mathrm{V}, \mathrm{Rd}}=221.56 \mathrm{kN}$

$$
\begin{aligned}
\mathrm{F}_{\mathrm{v} \cdot \mathrm{Rd}}= & \mathrm{A}_{\mathrm{v}} \mathrm{f}_{\mathrm{ybw}} /\left(\sqrt{3} \gamma_{\mathrm{M} 0}\right)=221.56 \mathrm{kN} \text { (EC3 Part 1-1 Clause 6.2.6(2)) } \\
& \mathrm{A}_{\mathrm{v}}=\mathrm{h}_{\mathrm{p}} \mathrm{t}_{\mathrm{bw}}=16.33 \mathrm{~cm}^{2} \\
& \mathrm{f}_{\mathrm{ybw}}=235.00 \mathrm{~N} / \mathrm{mm}^{2}
\end{aligned}
$$

\section{Joint shear resistance}

Shear resistance of the joint:

Failure Mode:

$\mathrm{V}_{\mathrm{Rd}}=221.56 \mathrm{kN}$

Beam web in shear

- Design check

Applied shear force:

$\mathrm{V}_{\mathrm{Ed}}=200 \mathrm{kN}$

Shear resistance:

$\mathrm{V}_{\mathrm{Rd}}=221.56 \mathrm{kN} \Rightarrow$ Design O.K.

\section{CONCLUSIONS}

In Eurocode 3 Part 1.8 devoted to the design of the structural joints, rules are provided for the evaluation of the resistance of moment resisting joints, but only little information is available as far as 
simple joints are concerned. In order to fill this gap, research works have been initiated at Liège University and, on the basis of these preliminary works, European recommendations have been later on prepared and agreed within the Technical Committee 10 "Connections" of the European Convention for Constructional Steelwork. The publication of these recommendations is scheduled in 2007. In a first possible future revision of the book it is intended to extend the scope of these recommendations to column bases and column splices.

\section{REFERENCES}

[1] Guillaume M.-L., Development of an European procedure for the design of simple joints (in French), Diploma work, Liège University/ CUST Clermont-Ferrand, July 2000.

[2] Eurocode 3 EN1993 Part 1-1, Design of Steel structures - General Rules and Rules for Buildings, CEN Brussels, EN 1993-1-1, May 2005

[3] Eurocode 3 EN1993 Part 1-8, Design of Steel structures - Design of Connections, CEN Brussels, EN 1993-1-8, May 2005

[4] BS 5950-1:2000, British Standard: Structural use of steelwork in building, Part 1, Code of practice for design - rolled and welded cross-sections.

[5] BCSA - SCI: Joints in Simple Construction, simple Connections, Publication 212, 2002.

[6] NEN 6770: Nederlands Normalisatie Instituut, NEN 6770 Staalconstructies TGB 1990, basiseisen.

[7] Report SG/TC-1OA:Verbindingen: Aanbevelingen voor normaal krachtverbindingen en dwarskrachtverbindingen, April 1998.

[8] Sedlacek G., Weynand K. and Oerder S.,Typisierte Anschlüsse im Stahlhochbau, DSTV, Stahlhbau-Verglagsges, Düsseldorf, 2000.

[9] Renkin S., Development of an European process for the design of simple structural joint in steel frames" (in French), Diploma work, Liège University, June 2003.

[10] ECSC Research Contracts 7210-SA/212 and 320, Frame Design including Joint Behaviour, 19931996, Final draft.

[11] Jaspart J.P., Renkin, S. and Guillaume M.L., European recommendations for the design of simple joints in steel structures, to appear in 2008 as a publication of the European Convention for Constructional Steelwork, Brussels.

[12] Gibbons C., Nethercot D., Kirby P. and Wang Y., An appraisal of partially restrained column behaviour in non-sway steel frames, Proc. Instn Civ. Engrs Structs \& Bldgs, 1993, 99, pp 15-28.

[13] Gaboriau M., Recherche d'une méthode simple de prédimensionnement des ossatures contreventées à assemblages semi-rigides dans l'optique de l'approche élastique de dimensionnement, Diploma work, Liège University, July 1995.

[14] Braham M. and Jaspart J.P., Is it safe to design a building structure with simple connections when they are know to exhibit a semi-rigid behaviour?, Journal of Constructional Steel Research, Volume 60, Issues 3-5, 2004, pp. 713-723.

[15] Jaspart J.P., Recent advances in the field of steel joints. Column bases and further configurations for beam-to-column joints and beam splices, Professorship Thesis, Department MSM, Liège University, 1997. 